\title{
Cognitive strategy accessibility as a function of task requirement in educable mentally retarded adolescents
}

\author{
LEONARD S. BLACKMAN \\ Teachers College, Columbia University, New York, New York 10027 \\ and \\ AGNES LIN BURGER \\ New York University, New York, New York 10003
}

\begin{abstract}
The accessibility of cognitive strategies was investigated in 115 mentally retarded adolescents $(\overline{\mathrm{CA}}=14.81, \mathrm{SD}=1.00 ; \overline{\mathrm{IQ}}=62.44, \mathrm{SD}=6.66)$. Three tasks, abstraction, categorical clustering, and sorting, were used. The accessibility of cognitive strategies was found to be related to explicitness of the task requirement. Data were interpreted to be supportive of a production deficiency in the mentally retarded.
\end{abstract}

In a free recall task involving categorizable material, normal subjects tend to organize stimuli into taxonomic categories (Jablonski, 1974). This phenomenon, known as clustering, is generally positively correlated with amount recalled by normal adults (Cofer, 1965; Tulving, 1968; Weist, 1972). This relationship is more tenuous, however, in both normal and mentally retarded children (Gerjuoy \& Winters, 1970; Jablonski, 1974). One explanation of this may revolve around the issue of the availability vs. accessibility of the clustering strategy. Tulving and his associates (Tulving \& Pearlstone, 1966; Tulving \& Psotka, 1971) contend that information may be available in a person's repertoire but not readily accessible. In other words, there may be a failure in the access mechanism which would account for unsuccessful retrieval of information. The quality of access mechanisms may also be germane to the utilization of cognitive strategies. Thus, mentally retarded children may have a cognitive strategy available to them but may not readily use it until they are explicitly told to do so. Congruent with this hypothesis is the fact that educable mentally retarded individuals, although inferior to normals of the same mental age (Griffith, Spitz, \& Lipman, 1959), can abstract relationships when the task instructions are explicit in requiring them (Griffith \& Spitz, 1958). Similarly, most mentally retarded individuals are able to

This study was supported by Grant HD 07329 from the National Institute of Child Health and Human Development, Department of Health, Education, and Welfare. The correlation data in this study were originally reported in the progress report by Leonard S. Blackman, Linda H. Bilsky, Agnes Lin Burger, and Harvey Mar entitled Cognitive Processes and Academic Achievement in Educable Mentally Retarded Adolescents. Research and Demonstration Center in the Education of the Handicapped, Teachers College, Columbia University, March 1975. This paper is sponsored by John J. Winters, Jr., who takes full editorial responsibility for its contents. sort according to conceptual categories when instructed to do so (McConkey \& Herriot, 1973).

In categorical clustering, as well as in the abstraction and sorting tasks, the stimulus items are amenable to being classified. This is probably accomplished by the application of underlying cognitive processes which involve hypothesis testing of the attributes associated with each item in order to discover interrelationships such as abstraction of a common property or sorting according to superordinate-subordinate hierarchies. Categorical clustering without external aids may or may not involve the recognition of categories embedded in the stimulus items but does require spontaneous organization of these items without having been instructed to do so by the experimenter. The abstraction and sorting tasks, however, require actively seeking hypotheses concerning likely relationships at the specific request of the experimenter. One conjecture is that without an external request, appropriate cognitive strategies may be available but not accessible to mentally retarded individuals. The purpose of the present study is thus to verify whether accessibility of cognitive strategies is a function of different levels of task requirement by investigating the interrelationships among two explicit-requirement tasks, abstraction and sorting, and a nonexplicitrequirement task, categorical clustering in free recall.

\section{METHOD}

\section{Subjects}

The subjects were 115 adolescents selected from the special classes for the educable mentally retarded in a number of junior high schools in the inner city of a large metropolitan area. There were 67 males and 48 females with a mean chronological age of 14.81 years $(\mathrm{SD}=1.00)$ and a mean $\mathrm{IQ}$ of 62.44 $(\mathrm{SD}=6.66)$. With the exception of one Peabody Picture Vocabulary Test, all IQ scores were based on either the Wechsler Intelligence Scale for Children or the Stanford-Binet Intelligence 
Scale administered no more than 2 years prior to this study. The subjects included in this study had reading grade equivalent scores of no less than 1.5 and were free from serious sensorymotor deficits and emotional or social maladjustment.

\section{Material and Procedure}

The subjects were administered the abstraction, categorical clustering, and sorting tasks. These tasks were administered individually to each subject in approximately two sessions over a 1- to 2-week period. The order of task administration was randomly determined. A brief description of each of the tasks follows.

Abstraction. This task was composed of one practice item and 20 test items which were administered orally. The subject was asked to tell how a triad of three conceptually similar words in each item were alike (e. g., elephant-mountain-whale).

Sorting. On this task, the subject was required to make five groups of equal size that "go together" from a randomly and simultaneously presented array of 15 line drawings. The pictures were to be placed onto a 5 (group) by 3 (instances) matrix board. The subject was asked to name the common objects depicted by the drawings before sorting them into groups based on common function or class. The represented categories included: containers, dwellings, things to read, tools, and transportation. After groupings were formed, verbal labels descriptive of those groupings were requested.

Categorical clustering. A list of 20 words (Rossi, 1963), consisting of five words from each of four conceptual categories (animals, body parts, clothing, and food), was presented to all subjects. After each presentation of the list, the subjects were simply asked to recall as many words from the list as they could. The 20 words were presented in a different randomized order on each of four trials, with the restriction that no two words from the same superordinate appear consecutively. Stimulus words were presented at the rate of $2 \mathrm{sec} /$ word and the recall intervais were subject paced.

Clustering scores were derived according to the following formula for the adjusted ratio of clustering (ARC) as previously employed by Gerjuoy and Spitz (1966) and Roenker, Thompson, and Brown (1971):

$$
A R C=\frac{O(R)-E(R)}{\operatorname{Max}(R)-E(R)},
$$

where $O(R)$ is observed clustering or number of times the name of a stimulus word is followed by another stimulus word from the same category during recall, $E(R)$ is the expected number of clusters (Bousfield \& Bousfield, 1966), and $\operatorname{Max}(R)$ is the maximum number of clusters possible given the items recalled.

\section{RESULTS AND DISCUSSION}

The product-moment correlations between Abstraction, Sorting, and Categorical Clustering scores were: Abstraction and Sorting, $.48(\mathrm{df}=113, \mathrm{p}<.001)$; Abstraction and Categorical Clustering, .09; and Sorting and Categorical Clustering, .02. A substantial relationship was found only between Abstraction and Sorting, whereas Categorical Clustering was related to neither. Inspection of the clustering data revealed that the subjects clustered very little; even by the last trial (Trial 4) they were clustering an average of less than one word above chance, and the mean ARC ratio over the four trials was .08 , which is very small compared to their maximum possible clustering of 1.00 . The correlation data, in conjunction with the clustering data, could be interpreted to mean that the accessibility of cognitive strategies is at least in part a function of the explicitness of the task requirement.

While subjects apparently used a comparable cognitive strategy on the explicit requirement tasks of Abstraction and Sorting, there was no evidence that this strategy was employed in the Categorical Clustering task, the instructions for which offered no external facilitation for the use of a cognitive strategy.

Another possible explanation for the lack of correlation between Categorical Clustering and Abstraction and Sortirig is that the Categorical Clustering score is the only one of the three obtained within the context of a memory task. Any speculation that this score reflects more of a memory than an organizational component, however, is disconfirmed by exceedingly low correlations between Categorical Clustering and other more obvious memory tasks in the original correlational matrix (see footnote) such as digit recall and pairedassociate learning.

These results may also be construed as supportive of Flavell's (1970) construct of a production rather than a mediational deficiency. The production deficiency is said to exist when potential mediational strategies are not spontaneously produced, although retarded individuals can be shown capable of using strategies if they are so instructed. A mediational deficiency applies to retarded individuals' inability to employ mediational strategies even when they are specifically instructed to do so. The interpretation of the results of the present study that retarded adolescents' utilization of a cognitive strategy is a function of task instruction explicitness lends support to the production deficiency hypothesis.

\section{REFERENCES}

Bousfield, A. K., \& Bousfield, W. A. Measurement of clustering and sequential constancies in repeated free recall. Psychological Reports, 1966, 19, 935-942.

COFER, C. N. On some factors in the organizational characteristics of free recall. American Psychologist, 1965, 20, 261-272.

Flavell, J. H. Developmental studies of mediated memory. In H. W. Reese \& L. P. Lipsitt (Eds.), Advances in child development and behavior (Vol. 5). New York: Academic Press, 1970. Pp. 181-211.

Geruuoy, I. R., \& Spitz, H. H. Associative clustering in free recall: Intellectual and developmental variables. American Journal of Mental Deficiency, 1966, 70, 918-927.

Geruuoy, I. R., \& Winters, J. J. Subjective organization by EMR adolescents in free recall: Bimodal presentation. American Journal of Mental Deficiency, 1970, 74, 509-516.

GRIfFITH, B. C., \& SPITZ, H. H. Some relationships between abstraction and word meaning in retarded adolescents. American Journal of Mental Deficiency, 1958, 63, 247-251.

Griffith; B. C., Spitz, H. H., \& Lipman, R. S. Verbal mediation and concept formation in retarded and normal subjects. Journal of Experimental Psychology, 1959, 58, 247-251.

Jablonski, E. M. Free recall in children. Psychological Bulletin, 1974, 81, 522-539. 
MCCONKEy, R..\& HerRiot, P. The relationship between category labeling and sorting with retarded adults. American Journal of Mental Deficiency, 1973, 77, 751-753.

Roenker, D. L., Thompson, C. P., \& Brown, S. ' C. Comparison of measures for the estimate of clustering in free recall. Psychological Bulletin, 1971, 76, 45-48.

Rossi, E. L. Associative clustering in normal and retarded children. American Journal of Mental Deficiency, 1963, 67, 691-699.

Tulving, E. Theoretical issues in free recall. In T. H. Dixon \& D. L. Horton (Eds.), Verbal behavior and general behavior theory. Englewood Cliffs, N.J: Prentice-Hall, 1968. Pp. 2-36.
Tulving, E., \& Pearlstone, Z. Availability versus accessibility of information in memory for words. Journal of Verbal Learning and Verbal Behavior, 1966, 5, 381-391.

Tulving, E., \& PsotkA, J. Retroactive inhibition in free recall: Inaccessibility of information available in the memory store. Journal of Experimental Psychology, 1971, 87, 1-8.

WEIST, R. M. Associative structure and free recall. Journal of Experimental Psychology, 1972, 94, 110-112.

(Received for publication May 24, 1976.) 